\title{
TECNOIMAGENS DA EDUCAÇÃO SEGUNDO VILÉM FLUSSER
}

\author{
Rodrigo Duarte ${ }^{1}$
}

\begin{abstract}
Resumo:
As reflexões de Vilém Flusser sobre a técnica apontam para o seu conceito de pós-história, o qual denota uma situação de predomínio das "tecnoimagens", em oposição à pré-história, na qual imperam as imagens convencionais, e à história, em que a escrita é o principal código fundante na sociedade. Na pós-história impera um modelo de comunicação de massa, no qual os discursos são "anfiteatrais" e atuam no sentido de "programar" as pessoas para que se tornem "funcionários" a serviço de "aparelhos", que agem automaticamente em total desconsideração das necessidades propriamente humanas. As tecnoimagens desempenham um papel preponderante nesse processo de programação das pessoas e podem ser exemplificadas por todas as superfícies bidimensionais como fotos, filmes, vídeos etc. As saídas para essa situação de jugo do ser humano se encontram, para Flusser, tanto na "arte enquanto embriaguez" quanto num modelo de educação que transcenda tanto a modalidade "industrial", tendencialmente superada pelo advento da informática, quanto a própria educação que nela se baseia, mas de modo unilateral.
\end{abstract}

Palavras-chave: Pós-história. Aparelhos. Programas. Arte como embriaguez. Imagem técnica.

\section{TECNOIMAGES OF EDUCATION ACCORDING TO VILÉM FLUSSER}

\begin{abstract}
:
Vilém Flusser's thoughts on technique point out to his concept of post-history, meaning a predominance of "technoimages", as opposed to pre-history, in which conventional images rule, and to history, in which writing is the main codifying process in society. In post-history, a model of mass communication rules, in which discourses are "amphitheatrical" and act to "program" people in order to transform them into "functionaries" on behalf of "apparatuses" that work automatically, totally disregarding human needs. Techno-images play a very important role in this programming process of people and may be exemplified by every bidimensional surface like photos, movies, videos etc. According to Flusser, the way to cast off the yoke of apparatuses lies in "art as inebriation" as well as in an education model that surpasses both the "industrial" modality, overcome by the advent of informatics, and the modality of education that is itself one-sidedly based on this cybernetic model.
\end{abstract}

Keywords: Post-history. Apparatuses, Programs, Art as inebriation. Technical image.

O pensamento de Vilém Flusser (1920-1991) sobre a técnica é tributário de sua noção de "pós-história", que não deve em absoluto ser confundida com os posicionamentos reacionários, os quais, há algumas décadas, infestaram a opinião pública mundial, sob a alegação de que o fim do então chamado "socialismo real" representou, juntamente com o "fim das utopias", o advento de uma situação em que nada mais se poderia esperar de um decurso histórico que projetasse um telos de emancipação para a humanidade. Essa deveria, portanto, se contentar, a partir de então, com o que já havia sido conquistado em termos de liberdade individual e prosperidade econômica altamente seletivas, como se sabe, tanto no seio das nações quanto em termos globais.

No caso de Flusser, a "pós-história" não designa esse estado em que nada mais propriamente acontece, mas uma situação, na qual existem tendências que - para o bem ou para o

1 Doutor em Filosofia pela Universität Gesamthochschule Kassel. Professor da Universidade Federal de Minas Gerais. E-mail: roduarte@ufmg.br. Lattes: http://lattes.cnpq.br/9952013182741941. 
mal - contrariam a noção de progresso, tal como vem sendo cultivada no Ocidente já há alguns séculos. Em Flusser, ela é uma concepção desenvolvida a partir de meados da década de 1970 e consolidada primeiramente na obra Pós-história. Vinte instantâneos e um modo de usar, a qual enfoca os âmbitos social, ético, político, tecnológico e estético, dentre outros, da contemporaneidade, sendo construída a partir de noções como as de "comunicação", "aparelho", programa", “funcionário" e "imagem técnica", ao lado de outras que aparecerão a seguir.

Para iniciar com a noção mais ampla dentre as mencionadas, pode-se considerar a concepção flusseriana de comunicação. O ponto de partida de Flusser é o fato de que a espécie humana se distingue por sua capacidade tanto de armazenar dados a partir das experiências vividas quanto de transmiti-los e o conceito de comunicação advém exatamente da transmissão coordenada e - eventualmente - recíproca dessas informações armazenadas nas diversas formas de memória (que podem ser naturais ou artificiais). Desse modo, a comunicação é considerada como uma das funções mais básicas da sociedade humana, sendo pressupostas capacidades complementares de armazenamento de informações, por um lado, e de geração de informações novas, por outro. Para Flusser, essas últimas são produzidas pelos diálogos, nos quais a troca de experiências gera a síntese de algo até então inexistente; mas há a necessidade de fixação desse algo num meio que o torne disponível para diálogo futuro, e esse tipo de transmissão de informações mediante o seu acúmulo constitui o que Flusser chama de discurso. Ele sugere que o par diálogo-discurso é um dado antropológico e que, portanto, pode ser encontrado numa infinidade de culturas humanas, se não mesmo em todas elas.

No caso da cultura ocidental, para Flusser, essa divisão comporta ainda subdivisões (que podem ocorrer, pelo menos parcialmente, também em outras culturas) dos diálogos em dois tipos - os circulares e os em rede - e dos discursos em quatro tipos: teatrais, piramidais, em árvore e anfiteatrais. Os diálogos circulares pressupõem uma comunicação direta, responsável e recíproca entre indivíduos e os em rede admitem certa frouxidão no trato das informações recebidas e transmitidas adiante. Os discursos teatrais são aqueles em que indivíduos expõem os seus pontos de vista de modo totalmente horizontal diante de uma plateia que lhe é imediatamente próxima. Os discursos piramidais pressupõem estruturas de poder rigidamente hierárquicas, enquanto nos em árvore a hierarquia é mediatizada por diferentes graus de expertise na matéria de que tratam. Os discursos anfiteatrais, por sua vez, estabelecem um emissor dirigindo-se a uma massa de receptores. Exemplos de cada um dos tipos de diálogo e discursos, levando em consideração os meios

\begin{tabular}{|c|c|c|c|c|}
\hline Q Povista Dialectus & Ano 9 & n. 17 & Maio - Agosto 2020 & p.166-181 \\
\hline
\end{tabular}


tecnológicos disponíveis à época em que Flusser escreveu o referido livro, são dados na chave abaixo:

\author{
Diálogos $\left\{\begin{array}{l}\text { Circulares (mesas redondas, parlamentos) } \\ \text { Rede (sistema telefônico, opinião pública) }\end{array}\right.$ \\ Teatrais (aulas, concertos) \\ Discursos Piramidais (exércitos, igrejas) \\ Árvores (ciência, artes) \\ Anfiteatrais (rádio, imprensa)
}

Cada modelo comunicacional, no que tange ao teor de responsabilidade e liberdade, pressupõe um par específico de diálogo/discurso sendo que o mais democrático desses pares é o composto pelo diálogo circular coligado ao discurso teatral - composição em que o discursante pode ser interpelado a qualquer momento pela plateia no sentido de esclarecer suficientemente a sua fala. Por questões de economia do texto não serão aludidas outras combinações possíveis desses pares, com exceção do par menos democrático de todos: o composto de diálogos em rede coligados a discursos anfiteatrais - muito específicos da contemporaneidade, no Ocidente, pois tais discursos podem ocorrer somente mediante meios de comunicação de massa. Nesse momento, pode-se começar a ter um vislumbre da situação pós-histórica, entendida como situação de crise do Ocidente, pois, segundo Flusser, aqui, “todo o espaço está ocupado pelas irradiações anfiteatrais e pelo diálogo em rede. [...] A crise atual da ciência deve ser pois vista no contexto da situação comunicológica da atualidade. Enquanto não houver espaço para a política, para diálogos circulares não elitários, a crise da ciência se apresenta insolúvel” (FLUSSER, 1983, p. 63).

Esse aspecto de crise do Ocidente torna-se ainda mais explícito quando Flusser estabelece a sua noção de "programa", a qual transita entre o seu sentido mais geral, de um plano estabelecido para determinada ação, e o mais restrito — e muito atual —, de software que faz funcionar o hardware de um dispositivo computacional. Esse último sentido tende a prevalecer na consideração da sociabilidade contemporânea, que, indiferente às demandas propriamente humanas, faz valer um modelo cibernético de sociedade, no qual as instituições são aparelhos e as pessoas se transformam paulatinamente em funcionários, cuja tarefa é fazer com que os aparelhos funcionem. Assim como no caso do predomínio do par diálogo em rede/discurso anfiteatral, para Flusser, a única saída para essa situação seria nos conscientizarmos do risco dessa desumanização e nos

\begin{tabular}{|l|l|l|l|l|}
\hline Q Povista Dialectus & Ano 9 & n. 17 & Maio - Agosto 2020 & p.166-181 \\
\hline
\end{tabular}


tornarmos jogadores mais hábeis que os aparelhos movimentados pelos programas automatizados que ameaçam a nossa liberdade:

\begin{abstract}
Em suma: o que devemos aprender é assumir o absurdo, se quisermos emancipar-nos do funcionamento. A liberdade é concebível apenas enquanto jogo absurdo com os aparelhos. Enquanto jogo com programas. É concebível apenas depois de termos assumido a política, e a existência humana em geral, enquanto jogo absurdo. Depende de se aprenderemos em tempo de sermos tais jogadores, se continuarmos a sermos "homens", ou se passaremos a ser robôs: se seremos jogadores ou peças de jogo. (FLUSSER, 1983, p. 31).
\end{abstract}

Em suma: o que devemos aprender é assumir o absurdo, se quisermos emancipar-nos do funcionamento. A liberdade é concebível apenas enquanto jogo absurdo com os aparelhos. Enquanto jogo com programas. É concebível apenas depois de termos assumido a política, e a existência humana em geral, enquanto jogo absurdo. Depende de se aprenderemos em tempo de sermos tais jogadores, se continuarmos a sermos "homens", ou se passaremos a ser robôs: se seremos jogadores ou peças de jogo. (FLUSSER, 1983, p. 31).

A relevância da noção de jogo para Flusser será objeto de consideração adiante. Por outro lado, a transposição da linguagem computacional para a sociedade pressupõe que haja formas eficientes de programação dos seres humanos e, de fato, elas abundam na ambiência pós-histórica, no sentido flusseriano do termo. Um dos exemplos mais eloquentes dados pelo autor é o dos shopping centers: nos mais típicos deles, se encontram obrigatoriamente pelo menos um supermercado e um cinema. Para o filósofo, esse é um par totalmente complementar, pois a freguesia do shopping center recebe a sua programação para o consumo no cinema e, imediatamente após a sua saída desse, realiza o próprio consumo no supermercado, preparando-se para ser, posteriormente, de novo programada no cinema para novas compras no supermercado. Nas palavras do próprio Flusser: "O supermercado e o cinema formam as duas asas de um ventilador que insufla na massa o movimento do progresso. No cinema a massa é programada para comportamento consumidor no supermercado, e do supermercado a massa é solta para reprogramarse no cinema" (FLUSSER, 1983, p. 70).

Esse exemplo pode ser considerado sintomático também tendo em vista o fato de que a programação do público consumidor ocorre na situação pós-histórica sobretudo por meio do que Flusser chama de "imagens técnicas" ou "tecnoimagens", das quais o cinema é um bom exemplo. Mas, na verdade, de acordo com o esquema que será explicitado a seguir, todas as superfícies bidimensionais que contenham informações visuais e que tenham sido produzidas por aparelhos constituem exemplos desse tipo de imagem que nos programa atualmente, assim introduzido por

\begin{tabular}{|c|c|c|c|c|}
\hline Q Povista Dialectus & Ano 9 & n. 17 & Maio - Agosto 2020 & p.166-181 \\
\hline
\end{tabular}


Flusser: "Planos como fotografias, telas de cinema e da TV, vidros das vitrines, tornaram-se os portadores das informações que nos programam. São as imagens, e não mais os textos, que são os media dominantes" (FLUSSER, 1983, p. 97).

Quando Flusser estabelece o imensamente superior poder de programação das imagens técnicas em comparação com os textos, que já foram predominantes em épocas passadas, ele tem em mente a sua narrativa, segundo a qual, as imagens tradicionais, feitas pela mão de seres humanos, foram, em tempos imemoriais, o primeiro "código fundante", o primeiro método que a humanidade inventou para se orientar no mundo, sendo que as pinturas rupestres constituem o melhor testemunho desse fato. Durante muito tempo tais imagens prosperaram e predominaram até que no terceiro milênio a.C., em algum lugar no Oriente médio, surgiu um novo tipo de código fundante: a escrita. Para Flusser, ela apareceu quando a disposição de elementos de modo circular, como num plano, foi posta pela primeira vez numa série com um sentido obrigatório de decodificação (no caso das escritas ocidentais de cima para baixo e da esquerda para a direita). O modo como isso pode ter acontecido foi exposto esquematicamente pelo próprio Flusser numa carta ao amigo Alex Bloch, datada de 16/12/1977 (FLUSSER, 2000, p. 106) ${ }^{2}$ :

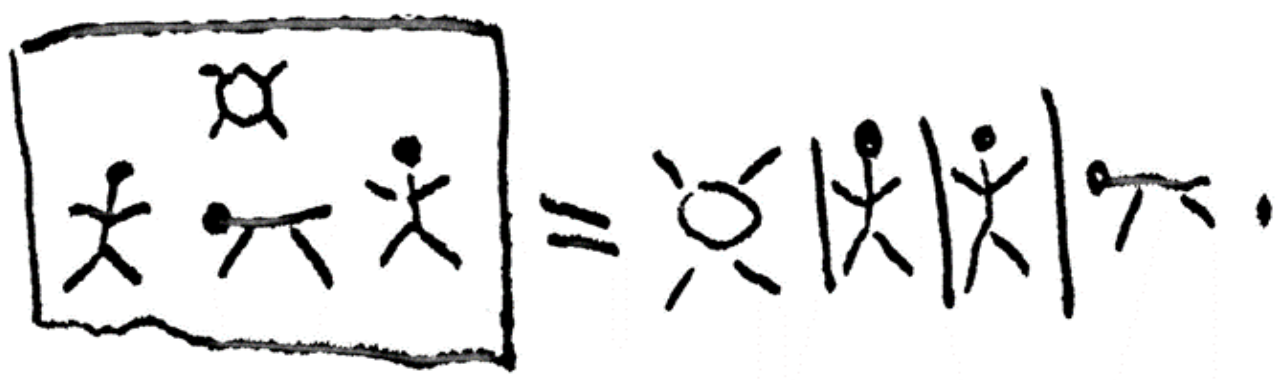

Para Flusser o significado de que a história tenha se iniciado com a escrita não diz respeito apenas ao fato de terem surgido aí os primeiros registros precisos sobre o passado humano, mas que a forma de pensar deixou de ser mágico-mítica e passou a ser, em virtude da linearidade do novo tipo de código predominante, lógica. Segundo o autor, "para a consciência estruturada por imagens a realidade é situação: impõe a questão da relação entre os seus elementos. Tal consciência é mágica.

2 Cf. “Umbruch der menschlichen Beziehungen?” In: FLUSSER, 1998b, p. 88.

\begin{tabular}{|l|l|l|l|l|}
\hline Q Povista Dialectus & Ano 9 & n. 17 & Maio - Agosto 2020 & p.166-181 \\
\hline
\end{tabular}


Para a consciência estruturada por textos a realidade é devir: impõe a questão do evento. Tal consciência é histórica. Com a invenção da escrita a história se inicia” (FLUSSER, 1983, p. 99). Para Flusser, ocorre, no entanto, uma espécie de "dialética da escrita", no sentido de que, se os textos surgiram com a incumbência de esclarecer os aspectos obscuros associados às imagens, o tipo de predomínio que vieram a exercer no Ocidente veio se mostrando paulatinamente cada vez mais opressor e, portanto, contraproducente, levando-se em conta o objetivo de esclarecimento em vista do qual a escrita foi primeiramente concebida: "Os textos, como as demais mediações [...] representam o mundo e encobrem o mundo, são instrumentos de orientação e formam paredes opacas de bibliotecas. Des-alienam e alienam o homem” (FLUSSER, 1983, p. 100).

Nesse momento, torna-se clara a associação do que Flusser chama de "pós-história" ao advento de um novo tipo de imagem, historicamente surgida em meados do século XIX com a invenção da fotografia, a saber, a supramencionada “tecnoimagem”. Para ele, essa surgiu com o objetivo de contrabalançar os riscos que a unilateralidade da consciência histórica encerrava, por meio de um novo tipo de código bidimensional que, diferentemente das imagens tradicionais, eram, sob vários aspectos, mediatizados por códigos lineares (escrita, expressões matemáticas, químicas etc., sem falar nas linhas de comando que produzem as atuais imagens digitais):

\begin{abstract}
Os textos se dirigiam, originalmente, contra-imagens, a fim de torná-las transparentes para a vivência concreta, a fim de libertar a humanidade da loucura alucinatória. Função comparável é a das tecnoimagens: dirigem-se contra os textos, a fim de torná-los transparentes para a vivência concreta, a fim de libertar a humanidade da loucura conceptual. $\mathrm{O}$ gesto de codificar e decifrar tecnoimagens se passa em nível afastado de um passo do nível da escrita, e de dois passos do nível das imagens tradicionais. É o nível da consciência pós-histórica. (FLUSSER, 1983, p. 100 et seq).
\end{abstract}

Para Flusser, a semelhança das tecnoimagens com as imagens tradicionais é apenas aparente, tendo em vista, dentre outras coisas, que essas são produzidas diretamente pela mão humana e aquelas o são pela mediação de aparelhos (câmeras convencionais, digitais, scanners etc.). Além da associação dessas à pré-história e daquelas à pós-história, o autor enfatiza também a diferença entre elas do ponto de vista ontológico: "as imagens tradicionais são pré-históricas; as imagens técnicas são pós-históricas. Ontologicamente, as imagens tradicionais imaginam o mundo; as imagens técnicas imaginam textos que concebem imagens que imaginam o mundo" (FLUSSER, 2002, p.13).

A complexidade maior das imagens técnicas, que se pode depreender da posição ontológica descrita acima, gera um poder de alienação inédito, uma vez que, para além do processo de simbolização, que, para a consciência histórica é evidente, sua qualidade visível cria a ilusão de

\begin{tabular}{|l|l|l|l|l|}
\hline Qevista Dialectus & Ano 9 & n. 17 & Maio - Agosto 2020 & p.166-181 \\
\hline
\end{tabular}


que elas sejam "objetivas" e que tenham um valor equivalente ao do que pode ser visto com os próprios olhos. Exatamente por isso, Flusser insiste na necessidade de uma decifração rigorosa das tecnoimagens, sob pena de uma submissão completa à programação dos aparelhos: “A mensagem das tecnoimagens deve ser decifrada e tal decodagem é ainda mais penosa que a das imagens tradicionais: é ainda mais "mascarada"” (FLUSSER, 1983, p. 102), isso porque, no caso da fotografia, por exemplo, "se amalgamam duas intenções codificadoras: a do fotógrafo e a do aparelho. $\mathrm{O}$ fotógrafo visa a eternizar-se nos outros por intermédio da fotografia. $\mathrm{O}$ aparelho visa a programar a sociedade através das fotografias para um comportamento que lhe permita aperfeiçoarse" (FLUSSER, 2002, p. 43).

É exatamente tendo em vista a complexidade dessa sua proto-forma, que serviu de base para todos os tipos posteriores de tecnoimagem, que Flusser denominou o seu livro sobre a fotografia de Filosofia da caixa preta, chamando a atenção para a característica desses dispositivos sobre os quais se percebe, imediatamente, apenas o seu input e o seu output, assim como para a necessidade de penetração no modo de ser mais profundo desses aparelhos:

\begin{abstract}
No caso das imagens técnicas, a situação é menos evidente. Por certo, há também um fato que se interpõe (entre elas e o seu significado): um aparelho e um agente humano que o manipula (fotógrafo, cinegrafista). Mas tal complexo "aparelho-operador" parece não interromper o elo entre a imagem e seu significado. Pelo contrário, parece ser canal que liga imagem e significado. Isto porque o complexo "aparelho-operador" é demasiadamente complicado para que possa ser penetrado: é caixa preta e o que se vê é apenas input e output. Quem vê input e output vê o canal e não o processo codificador que se passa no interior da caixa preta. Toda crítica da imagem técnica deve visar ao branqueamento dessa caixa. (FLUSSER, 2002, p.15).
\end{abstract}

A consideração dessa proto-forma de tecnoimagem evoluiu, ao longo do desenvolvimento da obra de Flusser, tanto para um vislumbre mais amplo do processo de apropriação do mundo pelo ser humano quanto para a inclusão de formas de imagem técnica de aparecimento posterior ao da fotografia convencional e do cinema, passando por formas eletrônicas analógicas, como a televisão e o vídeo, até chegar nas tecnoimagens digitais, cujo advento o filósofo presenciou ainda em vida. No trecho citado a seguir, ele indica como o ser humano parte de uma relação tátil com as coisas, que poderia ser considerada "quadridimensional" — porque inclui três dimensões espaciais e uma temporal - e vai abstraindo, progressivamente, uma a uma, das dimensões dessa experiência original até atingir a unidimensionalidade correlata à escrita, passando, naturalmente, pela bidimensionalidade das imagens tradicionais:

\begin{tabular}{|c|c|c|c|c|}
\hline Revista Dialectus & Ano 9 & n. 17 & Maio - Agosto 2020 & p.166-181 \\
\hline
\end{tabular}


A manipulação é o gesto primordial; graças a ele o homem abstrai o tempo do mundo concreto e transforma a si próprio em ente abstraidor, isto é homem propriamente dito. [...] As imagens abstraem, portanto, a profundidade da circunstância e a fixam em planos, transformam a circularidade em cena. A visão é o segundo gesto a abstrair (abstrai a profundidade da circunstância); graças a ele o homem transforma a si próprio em homo sapiens, ou seja, um ente que age conforme projeto. [...] Dezenas de milênios se passaram [...] até que tivéssemos aprendido a rasgar o tecido do contexto imaginado e a enviar os elementos sobre as linhas, a tornar as cenas "contáveis" (nos dois sentidos do termo), a desenrolar e desenvolver as cenas em processos, vale dizer, a escrever textos e a "conceber o imaginado". Consequentemente, a conceituação é o terceiro gesto abstraído (abstrai a largura da superfície); graças a ele o homem transforma a si próprio em homem histórico, em ator que concebe o imaginado. (FLUSSER, 2008, p. 16 et seq.).

O processo de abstração prossegue em direção ao estabelecimento das tecnoimagens e isso ocorre mesmo quando se percebe que os esforços anteriores de abstração tiveram a sua eficácia relativizada por circunstâncias inicialmente imprevistas. A metáfora que Flusser usa para explicar a passagem da escrita à tecnoimgem enquanto código predominante é a de que os textos são colares feitos de pedrinhas, nas quais o fio que as unia se desmancha e elas se espalham, como quanta, num universo caótico, que não pode ser nem manipulado, nem visto e nem mesmo conceptualizado. $\mathrm{O}$ processo de abstração pode, entretanto, seguir em frente, já que as pedrinhas (= calculus) que anteriormente compunham o colar são "calculáveis":

E, uma vez calculadas, podem ser reagrupadas em mosaicos, podem ser "computadas", formando então linhas secundárias (curvas projetadas), planos secundários (imagens técnicas), volumes secundários (hologramas). [...] Em consequência, o cálculo e a computação são o quarto gesto abstraidor (abstrai o comprimento da linha) graças ao qual o homem transforma a si próprio em jogador que calcula e computa o concebido. (FLUSSER, 2008, p. 17).

Esse mesmo processo pode ser descrito, de modo mais crítico, no sentido de que a cada grau de abstração corresponde um nível correspondente de estranhamento relativo à presença do ser humano no mundo, de modo que o primeiro nível faz surgirem as imagens tradicionais, o segundo nível a escrita, e o terceiro nível as tecnoimagens (ou imagens técnicas). De acordo com o diagrama abaixo, cada um desses níveis, como já assinalado, se relaciona a um estágio da civilização, que, por sua vez, corresponde a um tipo de experiência humana: o estranhamento (1) leva ao estabelecimento das imagens tradicionais e caracteriza a pré-história; o estranhamento (2) leva à criação da escrita e e corresponde à história; o estranhamento (3) produz as técnico-imagens e se conecta do advento da pós-história ${ }^{3}$ :

3 Diagrama adaptado de “Umbruch der menschlichenBeziehungen?” In: FLUSSER, 1998, p. 107.

\begin{tabular}{|c|c|c|c|c|}
\hline Revista Dialectus & Ano 9 & n. 17 & Maio - Agosto 2020 & p.166-181 \\
\hline
\end{tabular}




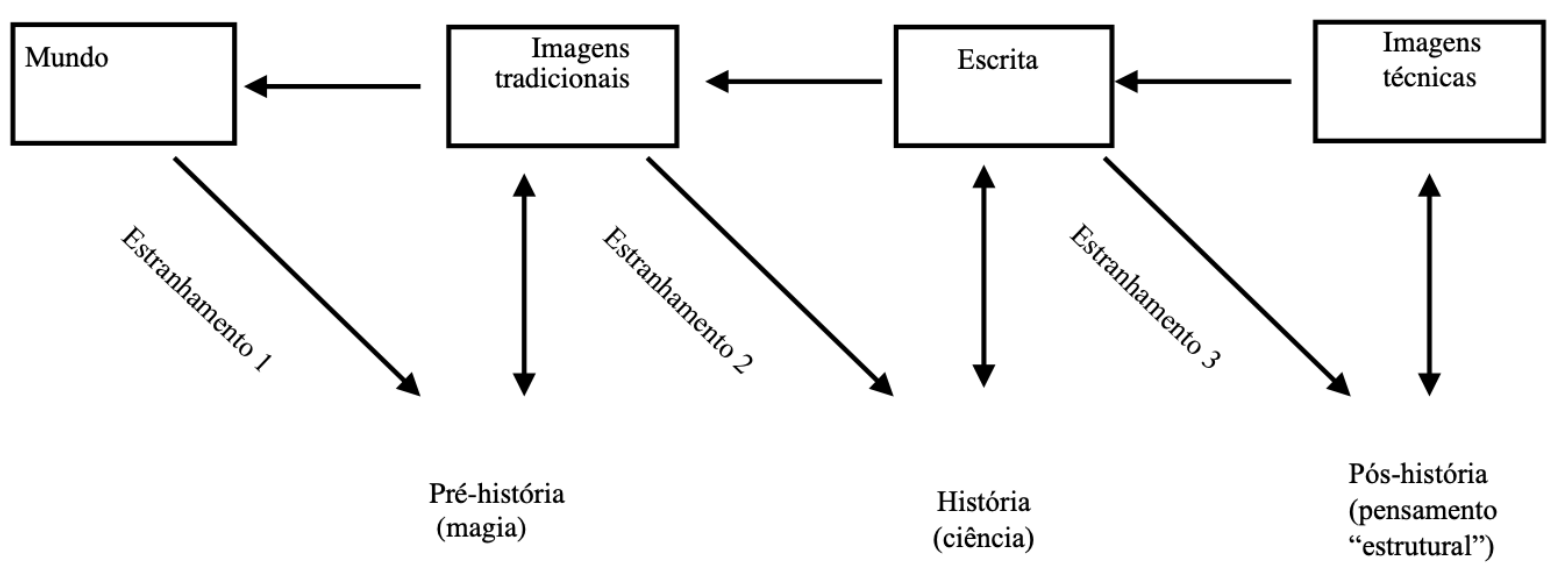

Vale observar que o termo "estranhamento", nesse contexto, é próximo do conceito de alienação, o qual, por sua vez, tem uma origem - familiar a Flusser — nas indagações de Hegel sobre as relações eu-mundo na Fenomenologia do espírito. Reportando-se a páginas importantes dessa obra, Flusser compreende aquelas relações como um processo agonístico, frequentemente muito doloroso, e o escape que a civilização ocidental moderna encontrou para esse tipo de sofrimento foi o da cooptação das consciências em formas cada vez mais sofisticadas de alienação, para as quais a fixação nos aspectos sensoriais dos perceptos é um dado fundamental:

As sensações não são ainda nem eu nem mundo. "Eu" e "mundo" não passam de extrapolações abstratas da sensação concreta. A experiência da sensação faz esquecer "eu" e "mundo". O filme, a TV, a notícia sensacional, o jogo de futebol divertem a consciência da tensão dialética "eu-mundo", porque são anteriores a esses dois polos. (FLUSSER, 1983, p. 114).

Esse posicionamento de Flusser sobre o sensacionalismo nas relações das consciências com a realidade leva-o a uma crítica implacável ao divertimento, na qual ressoa a sua advertência contra o predomínio dos discursos anfiteatrais nas atuais sociedades hiper-industrializadas, dominadas pelos meios de comunicação de massa:

Divertimento é acúmulo de sensações a serem eliminadas indigeridas. Uma vez posto entre parênteses mundo e Eu, a sensação passa sem obstáculo. Não há nem o que deve ser digerido, nem interioridade que possa digeri-lo. Não há intestino nem necessidade de intestino. O que resta são bocas para engolir a sensação, e ânus para eliminá-la. A sociedade de massa é sociedade de canais que são mais primitivos que os vermes: nos vermes há funções digestivas. (FLUSSER, 1983, p. 115 et seq.). 
Mas Flusser não concebe a contemporaneidade apenas como esse locus de manipulação produzida por meios tecnológicos cada vez mais sofisticados, nos quais destaca-se o aspecto alienador das tecnoimagens. O seu potencial libertador será objeto de consideração adiante e um elo importante para se compreender o modo como, para o filósofo, isso ocorre é o seu enfoque sobre a arte. Para ele, a criação artística possui parentesco com o consumo seletivo de drogas que caracteriza praticamente todas as culturas humanas, no sentido de que elas, a exemplo do que se viu quanto ao entretenimento, auxiliam o indivíduo a suportar o peso que a civilização exerce sobre os seus ombros. Mas, diferentemente das drogas químicas, cuja "viscosidade ontológica" suaviza a percepção da realidade, e que, mediante o seu abuso, provocam dependência fisiológica, destruindo, com isso, o indivíduo do ponto de vista físico e psíquico, a embriaguez propiciada pela arte, tanto em quem cria obras quanto em quem as compreende adequadamente, apresenta-se como um meio para a instauração do imediato e, com isso, projeta a possibilidade de um mundo verdadeiramente humano, para além da programação pelos aparelhos, a qual transforma pessoas em funcionários por meio do uso unilateral de tecnoimagens. Na definição de Flusser,

A arte é o órgão sensorial da cultura, por intermédio do qual ela sorve o concreto imediato. A viscosidade ambivalente da arte está na raiz da viscosidade ambivalente da cultura toda. [...] Ao publicar o privado, ao "tornar consciente o inconsciente", é ela mediação do imediato, feito de magia. Pois tal viscosidade ontológica não é vivenciada, pelo observador do gesto, como espetáculo repugnante, como o é nas demais drogas, mas como "beleza". E a cultura não pode dispensar de tal magia: porque sem tal fonte de informação nova, embora ontologicamente suspeita, a cultura cairia em entropia. (FLUSSER, 1983, p. 142 et seq.).

A compreensão do termo "entropia" no contexto do projeto de dominação por parte dos aparelhos, na situação pós-histórica, é fundamental para se avaliar o modo como a arte pode ser totalmente libertadora nesse contexto. Tais aparelhos, tanto no sentido mais literal quanto no figurado, são dispositivos cibernéticos, cujo funcionamento depende do aporte contínuo de informação nova no sentido de evitar a sua paralisação devido a um processo entrópico. Desse modo, os aparelhos admitem a existência da arte no contexto pós-histórico, em virtude de sua propriedade de gerar continuamente informação nova. Mas o fato de essa informação nova não ser controlável a priori pelos aparelhos, tendo em vista o seu alto teor de novidade, põe em cheque a capacidade que esses têm de transformar pessoas em funcionários, assim como de manter e aprofundar essa transformação: "Os aparelhos não podem, na situação atual, simplesmente recuperar o gesto da arte, e transformá-lo em funcionamento. Se entorpecerem tal gesto, cairiam em redundância por falta de informação nova. Se recuperassem a arte, os aparelhos se condenariam a si

\begin{tabular}{|l|l|l|l|l|}
\hline Q Povista Dialectus & Ano 9 & n. 17 & Maio - Agosto 2020 & p.166-181 \\
\hline
\end{tabular}


próprios: funcionariam em pronto morto" (FLUSSER, 1983, p. 143). É por isso que Flusser caracteriza a arte como o gesto mais revolucionário, mais libertador e mais promissor para um futuro efetivamente humano.

Essa possibilidade que Flusser vê na criação artística conduz à reflexão que ele faz sobre a educação. Segundo o filósofo, de acordo com uma antropologia que remonta à Grécia antiga, o ser humano seria um ente estranho no mundo sensível, que teria sido exilado para ele oriundo do mundo das ideias imutáveis. No seu local de origem, o ser humano teria conhecido essas ideias em sua ordem lógica e teria vivido na própria theoria (no sentido etimológico de “contemplação de Deus"); ao ser exilado, porém, ele teria se esquecido das ideias, uma vez que, durante a sua queda ao mundo fenomênico, atravessou o Lethos, o rio do esquecimento. Por isso, de acordo com Flusser, a concepção de educação na Antiguidade clássica apontava para uma recuperação dessa natureza suprassensível da humanidade, tornando esse processo a sua tarefa primordial:

A escola seria o lugar do Des-esquecimento, o lugar da redescoberta das ideias, portanto o lugar da desalienação, da salvação, da sabedoria. O propósito da cidade seria precisamente o de abrir espaço para o lazer (scholé), para a escola. A escola, esse lugar da teoria, se tornaria possível graças à política, e a política graças à economia. O propósito da economia seria possibilitar a liberdade política, e o propósito de tal liberdade seria possibilitar a escola. Os escolásticos, os filósofos, seriam destarte os reis da cidade. (FLUSSER, s/d, p. 1).

Para Flusser, a partir do advento da Idade Moderna, com o desenvolvimento do capitalismo, esse ideal da escola enquanto local de contemplação das verdades eternas vai sendo progressivamente erodido até que, com o surgimento da revolução industrial, a pirâmide que tinha a teoria "pura" no seu topo se inverte, de modo que a economia - antes subordinada à política, que, por sua vez, se subordinava àquela contemplação das ideias - passa a ocupar o lugar determinante e, mediante o conceito de "tecnologia" (= técnica mediatizada pela teoria), o próprio saber teórico passar a obedecer aos seus ditames e jamais conquistará novamente o lugar independente outrora ocupado: "Em termos da filosofia platônica: a escola, originalmente lugar da filosofia, passou a ser, na sociedade moderna, lugar da vida ativa, e passará, no futuro, a ser lugar da escravidão econômica do eterno retorno" (FLUSSER, 1983, p. 149). Essa mudança no lugar da educação se reflete estruturalmente na organização dos níveis de ensino na escola industrial, que, por sua vez, espelha a hierarquia social estabelecida a partir da consolidação do modo de produção capitalista:

\begin{tabular}{|c|c|c|c|c|}
\hline Revista Dialectus & Ano 9 & n. 17 & Maio - Agosto 2020 & p.166-181 \\
\hline
\end{tabular}


A escola burguesa está dividida em três níveis: no primário, lugar de informação do proletariado para o manejo das máquinas produtoras de obras; no secundário, lugar de informação da burguesia e do proletariado aburguesado para o controle das máquinas e do proletariado; e no superior, lugar de elaboração de novas teorias (modelos), pela burguesia. Em todos estes três níveis os dados (as ideias) vão sendo transmitidos de um emissor (professor), para serem aramados na memória do receptor (aluno). Embora haja duas disciplinas (a lógica e a matemática), que tratam do processamento de tais dados, o acento da escola burguesa é sobre a transmissão de dados. Tais dados são catalogados segundo o critério epistemológico vigente no século passado [século XIX/rd]: em dados relativos à natureza inanimada (físicos), à animada (biológicos) e à cultura (humanidades). Estes três característicos (SIC) da escola burguesa: (a) transmissão de dados, (b) negligência de processamento de dados, e (c) catalogação ultrapassada de dados, tornam a escola burguesa inoperante no contexto que está surgindo. (FLUSSER, s/d, p. 2).

O referido "contexto que está surgindo" diz respeito ao fato de que, à medida que sociedades (especialmente aquelas mais desenvolvidas em termos capitalistas) superam a condição de "industrializadas" e ingressam numa fase pós-industrial, alguns elementos de contraprodutividade do modelo de educação adequado à sociedade estruturada em função da indústria tornam-se cada vez mais evidentes: "A escola industrial é ilha arcaica no oceano das comunicações de massa: tornou-se antifuncional porque funciona em sentido oposto ao do fluxo das mensagens" (FLUSSER, 1983, p. 148). Um modo de compreender isso bem diz respeito aos supramencionados modelos de comunicação, tendo em vista a natureza dos discursos característicos da escola tradicional: eles são teatrais, enquanto "extra-muros" os discursos predominantes são anfiteatrais, i.e., aqueles característicos da cultura de massas. Flusser associa essa discrepância à passagem, a qual se encontra em pleno curso, da história (situação de predomínio da escrita) à pós-história (momento de prevalência das tecnoimagens), assinalando também o advento de uma nova antropologia, na qual o ser humano cada vez mais passa a ser definido pela lida com dados informacionais, com métodos de programação cibernética, nos quais ele pode tanto programar quanto ser programado:

\footnotetext{
A atual mutação pela qual estamos passando (e a qual defino como passagem para a póshistória no meu ensaio recentemente publicado), implica em substituição da antropologia classicamente ocidental por outra. O homem não mais é concebido ente provindo do reino das ideias, mas ente programado por informações herdadas e adquiridas. A diferença decisiva está no fato de ser o programa conjunto de informações que surge pelo jogo do acaso. Tal reformulação da antropologia pressupõe e implica nova reformulação do conceito "teoria". Esta deixa de ser manipulação e criação de ideias adaptáveis à obra, e passa a ser estratégia de programação, isto é: jogo deliberado com o acaso. E a escola, lugar da teoria, passa a ser lugar de programação da sociedade, e lugar da elaboração de programas. (FLUSSER, s/d, p. 2).
}

Nessa nova situação, a supra-referida estrutura disciplinar da escola típica da sociedade industrial, que estipula conteúdos respectivamente correspondentes aos âmbitos físico, biológico e

\begin{tabular}{|l|l|l|l|l|}
\hline Q Povista Dialectus & Ano 9 & n. 17 & Maio - Agosto 2020 & p.166-181 \\
\hline
\end{tabular}


humanístico, tende a ser substituída por outra, cuja ênfase se encontra em aspectos formais, principalmente relacionados à capacidade de computar e processar dados e não de acumular conhecimentos que podem ser mais eficientemente armazenados em memórias artificiais: "Novas disciplinas 'formais', não 'materiais', como o é a informática, a cibernética, a teoria das decisões e dos jogos vão se estabelecendo, e vão ocupando o centro do interesse. Pois tais disciplinas não cabem nos 'currículos 'da escola industrial, já que 'cruzam 'seus ramos” (FLUSSER, 1983, p. 148).

Por outro lado, uma inserção completa dos parâmetros educacionais na estrutura de uma sociedade pós-histórica não significaria, imediatamente, a instauração da "escravidão econômica" sobre a qual se falou acima, uma vez que, por razões que se mostrarão adiante, há dois modelos de educação, de sentidos opostos, na situação pós-histórica: "Duas tendências rumo à escola do futuro podem, desde já, ser discernidas. A primeira visa programar programadores, a segunda analistas de sistemas. A primeira representa a ameaça da robotização totalitária, a segunda da esperança de uma forma nova, e jamais dantes sonhada, de liberdade" (FLUSSER, s/d, p. 3).

A plausibilidade desse segundo modelo de educação pode ser buscada em seu parentesco com a arte, no que tange à sua semelhança com um tipo de embriaguez que, em vez de produzir dependência química e destruição física e psíquica dos indivíduos, produz beleza e projeta, com isso, uma volta por cima em relação ao poder — a princípio, aparentemente inexpugnável — dos aparelhos. A exemplo da arte, enquanto meio de eliminar mediações e de pôr em cheque a programação pelos aparelhos, “a escola do futuro deverá necessariamente permitir abertura rumo à experiência imediata, sob pena da sociedade totalitária cair em entropia. O dilema que confronta a programação aparelhística re-aparece" (FLUSSER, 1983, p. 149).

Mas assim como a liberdade a ser conquistada por esse modelo de escola do futuro será "nunca dantes sonhada", em função de certas características suas a serem mais bem compreendidas, também o seu correlato em termos da educação artística produzirá uma modalidade inusitada de criação que, diferentemente da tradicional separação entre a "Escola Politécnica" e a "Escola de Belas Artes", terá como objetivo a síntese desses dois âmbitos complementares da atividade humana: "O artista puro virou anacronismo, a unidade original do verdadeiro, bom e belo ficou restabelecida pelos aparelhos, mas, desta vez, sob forma de know-how, da 'tecnologia'. Com tal estratégia os aparelhos procuram recuperar a dimensão criativa do homem que os ameaça" (FLUSSER, 1983, p. 151).

De acordo com Flusser, isso poderá ocorrer a partir de necessidades dos próprios aparelhos, sendo as mais imediatas a elaboração de programas que façam funcionar o mega-

\begin{tabular}{|c|c|c|c|c|}
\hline Revista Dialectus & Ano 9 & n. 17 & Maio - Agosto 2020 & p.166-181 \\
\hline
\end{tabular}


aparelho em que a sociedade poderá estar se transformando. Suas necessidades mais mediatas, ligadas à carência de informação nova nos programas, abrem caminho para a reversão dialética que, de modo inédito, levará à vitória sobre os aparelhos, na medida em que poderá restaurar o gosto para a arte e para a filosofia: "Os institutos tecnológicos futuros exigirão conhecimento de informática, cibernética, teoria dos conjuntos e dos jogos. Isto proporcionará aos alunos recuo 'irônico 'com relação aos aparelhos e seu funcionamento. E tal distanciamento teórico será convite para o mergulho em direção da 'experiência imediata'. Convite à filosofia" (FLUSSER, 1983, p. 151).

Para Flusser, o que está por trás dessa possibilidade é, como já se sugeriu, uma nova antropologia e, para ser mais explícito, nela se trata de substituir o homo faber, o "agente" que se consolidou na civilização industrial, pelo homo ludens, que explorará às últimas consequências, no âmbito pós-histórico, o parentesco dos programas computacionais com os jogos, lembrando que vários desses softwares produzem efetivamente jogos, i.e., games. Desse modo, "o gesto da programação é um jogo com dados, e a antropologia emergente é a do 'homo ludens'. A escola burguesa está condenada por ser lugar para futuros agentes, não para futuros jogadores. E 'teoria' do jogador é estratégia, e não modelação, como o é do agente. A escola enquanto lugar da teoria deverá necessariamente ser no futuro lugar de estratagemas" (FLUSSER, s/d, p. 3).

Que seja enfatizado o lugar de destaque que a ideia de homo ludens, tomada emprestada de Johan Huizinga (cf. HUIZINGA, 2019, passim), ocupou, sob vários aspectos e desde muito cedo, no pensamento de Flusser. Vale lembrar também que, na construção do seu pensamento, bem antes da consolidação dos seus filosofemas sobre a pós-história, nos quais se explicita a possível base material desse homo ludens, o filósofo já tinha aventado a hipótese — ainda bastante idealizada - de que o tipo humano afro-brasileiro apresentava as características lúdicas que ele veio, posteriormente, a atribuir ao "novo homem" num sentido mais geral. Na sua Fenomenologia do brasileiro, consta: “O que importa é que está surgindo no Brasil um autêntico, espontâneo, não deliberado homo ludens. Um homem que trocou a realidade social e econômica por outra, igualmente real, mas de estrutura e de vivência inteiramente diferente" (FLUSSER, 1998a, p. 101). No que tange, entretanto, à possibilidade libertadora — "alternativa" — da pós-história, Flusser afirma que a programação avançada dos processos produtivos poderá fornecer ao ser humano a infraestrutura material para a sua transformação em homo ludens, uma vez que, numa recolocação em bases cibernéticas da etimologia da palavra escola (do grego scholé = ócio), o seu lazer será, antes de tudo, criativo, mas também implicitamente produtivo:

\begin{tabular}{|c|c|c|c|c|}
\hline Revista Dialectus & Ano 9 & n. 17 & Maio - Agosto 2020 & p.166-181 \\
\hline
\end{tabular}


A outra tendência, a "alternativa", se manifesta menos obviamente. Partindo da mesma antropologia da primeira, a do "homo ludens", tal tendência constata que a mutação mais profunda da vida, provocada pela desvalorização do trabalho, é o aumento quantitativo do lazer disponível. A decadência dos valores burgueses (os da vida ativa), e a subida dos novos valores (os do jogo com o acaso, "jeux du hasard”), se dão no espaço aberto para o lazer pela programação do trabalho. Já que lazer é sinônimo de escola, isto implica que a maior parte do tempo vital será passado na escola, e esta ocupará, pelo menos quantitativamente, lugar semelhante ao ocupado pela escola pré-renascentista. Com a diferença decisiva que não será lugar de contemplação e de prece, mas lugar de jogos.(FLUSSER, s/d, p. 4).

Esse posicionamento de Flusser explicita bem a frase — que pode ter soado um pouco enigmática - citada no início desse artigo a respeito da noção de "programa", a saber: "A liberdade é concebível apenas enquanto jogo absurdo com os aparelhos” (FLUSSER, 1983, p. 31). Tal "jogo absurdo" pode ser concebido, depois de bem entendidos a noção flusseriana de aparelho e o ponto de vista do filósofo sobre a educação emancipadora na pós-história enquanto realização radical da liberdade, como algo que não mais se realizará "aquém dos aparelhos", mas para além deles, na medida em que, a partir daquele modelo de educação, os indivíduos "não mais programarão programas, mas os próprios aparelhos. Viverão transaparelhisticamente. A sociedade totalitária virará' democracia 'em sentido jamais imaginado anteriormente" (FLUSSER, 1983, p. 152).

É compreensível que, a partir de uma vivência tão miserável em escala global como a do presente, tal vislumbre de uma "Escola na qual todos são reis, em vez de serem escravos" (FLUSSER, 1983, p. 152) possa parecer excessivamente utópico, beirando o irresponsavelmente visionário. Mas o próprio Flusser considera essa uma "possibilidade remota", que, entretanto, "está no programa dos aparelhos" (FLUSSER, 1983, p. 152). Sua conclusão, a qual leva em conta o enorme poder do automatismo nos processos que afetam simultaneamente a vida de muitos milhões de indivíduos, aponta para um posicionamento eminentemente crítico e atento às necessidades propriamente humanas, sem o qual não faria sentido nem mesmo formular o conceito de liberdade:

\footnotetext{
A primeira tendência rumo ao totalitarismo é, atualmente, a mais forte E, dada a automaticidade autônoma de decisões humanas pelas quais funcionam os aparelhos, tende a realizar-se. No entanto, a outra tendência também se manifesta. Não resta dúvida para nós, os que ainda estamos engajados em favor da liberdade e contra a pseudo-felicidade da vida consumidora, em qual das duas tendências devemos nos engajar. (FLUSSER, s/d, p. 5).
}

Diante da questão concreta sobre se, mesmo com o nosso engajamento, ainda teremos tempo de fazer valer o ponto de vista humano antes que a transformação das pessoas em funcionários seja completada, Flusser sugere que, taticamente, empenhemos esforços no

\begin{tabular}{|l|l|l|l|l|}
\hline Qevista Dialectus & Ano 9 & n. 17 & Maio - Agosto 2020 & p.166-181 \\
\hline
\end{tabular}


retardamento do processo de desumanização que está em curso: "A estratégia da hesitação se revela portanto não totalmente negativa: retardar o progresso rumo à robotização, para permitir ao acaso da democratização espaço e tempo" (FLUSSER, 1983, p. 152).

\section{Referências}

DUARTE, Rodrigo. Pós-história de Vilém Flusser: gênese-anatomia-desdobramentos. São Paulo, Annablume, 2012.

FLUSSER, Vilém. Briefe an Alex Bloch. Göttingen: European Photography, 2000.

1998a.

Fenomenologia do brasileiro: Em busca de um novo homem. Rio de Janeiro: Eduerj,

Filosofia da caixa Preta: Ensaios para uma futura filosofia da fotografia. Rio de Janeiro: RelumeDumará, 2002.

Kommnunikologie. Frankfurt amMain: FischerVerlag, 1998b.

. Medienkultur. Frankfurt am Main: Fischer Verlag, 1997.

. O universo das imagens técnicas: Elogio da superficialidade. São Paulo, Annablume, 2008.

. Pós-história: Vinte instantâneos e um modo de usar. São Paulo: livraria Duas Cidades, 1983.

Pós-história e educação, [Online]. Flusser Brasil, s.d.. Disponibilidade em: http://www.flusserbrasil.com/aula74.pdf acesso em: 12/05/2020.

HUIZINGA, Johan. Homo Ludens: o jogo como elemento da cultura. Tradução: João Paulo Monteiro; revisão de tradução: Newton Cunha. 9a edição: revista e atualizada. São Paulo: Perspectiva, 2019.

\begin{tabular}{|c|c|c|c|c|}
\hline Qenista Dialectus & Ano 9 & n. 17 & Maio - Agosto 2020 & p.166-181 \\
\hline
\end{tabular}

